\title{
İhmal Edilmiş Patella Dislokasyonunda Uygulanan Total Diz Protezi
}

\author{
Total Knee Arthroplasty for Neglected Patellar Dislocation
}

\author{
Hasan Göçer, Alper Çıraklı, Nevzat Dabak \\ Ondokuz Mayıs Üniversitesi Tıp Fakültesi, Ortopedi ve Travmatoloji Anabilim Dalı, Samsun, Türkiye
}

\section{Özet}

Travma sonrası inmal edilmiş patella dislokasyonu oldukça nadir görülmektedir. Bu hastalarda hayatın ilerleyen dönemlerinde dizde osteoartritik değişiklikler gelişmekte ve buna bağlı olarak da ciddi derecede şikayetlere sebep olmaktadır. Literatürde çok az sayıda olgu bildirilmekle birlikte bu hastalar total diz artroplastisi ile tedavi edilmektedirler. Her cerrahın tedavi planında değişiklikler olmakla birlikte kabul edilmiş standart bir cerrahi teknik bulunmamaktadır. $\mathrm{Bu}$ olgulardaki amaç patellanın femoral olukta olması ve ekstansiyon mekanizmasının tam çalıştığı fonksiyonel bir diz eklemi elde etmektir. Yazımızda travma sonrası tedavi edilmemiş patella çıkı̆ı nedeniyle diz osteoartriti gelişen ve total diz artroplastisi uygulanan olgu literatür eşliğinde değerlendirilmiştir. (Haseki Tıp Bülteni 2014; 52: 140-3)

Anahtar Sözcükler: Patella, dislocation, trauma, total knee arthroplasty

\begin{abstract}
Neglected permanent post-traumatic patellar dislocation is rarely seen. In this group of patients, secondary osteoarthritis may develop within years, consequently, patients suffer from pain. In the literature, there have been a few cases treated with total knee arthroplasty. Although each surgeon's treatment plan changes, no standard surgical technique has been adopted. The aim in these cases, is to keep the patella located in the femoral groove and to achieve full knee extension. In this paper, a patient with osteoarthritis due to post-traumatic patellar dislocation who has undergone total knee arthroplasty is evaluated in the light of the literature. (The Medical Bulletin of Haseki 2014; 52: 140-3)
\end{abstract}

Key Words: Patella, dislokasyon, travma, total diz artroplastisi

\section{Olgu}

Elli altı yaşında $74 \mathrm{~kg}$ ağırlığında bayan hasta sol dizde ağrı, diz hareketlerinde kısıtlıık ve yürüme güçlüğü şikayetleri ile polikliniğimize başvurmuştur. Hikayesinden yaklaşık 35 yı önce sol dizine aldığı darbe sonrası dizde ağrı ve şişlik olması nedeniyle istirahat, buz tatbiki ve analjezik-antienflamatuar ilaç tedavisi uygulandığı öğrenildi. Hastanın mevcut tedavi ile ağı şikayeti gerilemiş, ancak diz dış kısmındaki şişlik sertleşerek devam etmiş ve diz hareketlerini kısıtlamış. Fizik muayenede patellanın diz anterolaterine yerleşmiş olduğu görüldü. Diz fleksiyonu pasif olarak yaklaşık $110^{\circ}$ idi ve ekstansiyon kısıtlılığı yoktu. Dizde laksite ve liagament hasarı tesbit edilmedi. Direkt 
grafide tibia ve femur eklem yüzeyinde ileri derecede evre-3 osteoartritik değişiklikler ve patellanın laterale disloke olduğu görüldü (Şekil 1). Manyetik rezonans görüntülemede (MRG) lateral patellar dislokasyon, medial retinakulumda yırtık, femoral sulkusta düzleşme ve eklem yüzeylerinde kıkırdak defekti tespit edildi (Şekil 2).

Epidural spinal anestezi ve turnike eşliğinde standart medial parapatellar insizyon uygulandı. Cilt ve cilt altı katlar geçildi. Patellanın laterale disloke olduğu ve quadriseps tendonun patella proksimalinde lateralde devam ettiği görüldü. Vastus medialis kasının hipertrofik ve quadriseps tendonunun lateraline kadar devam ettiği görüldü (Şekil

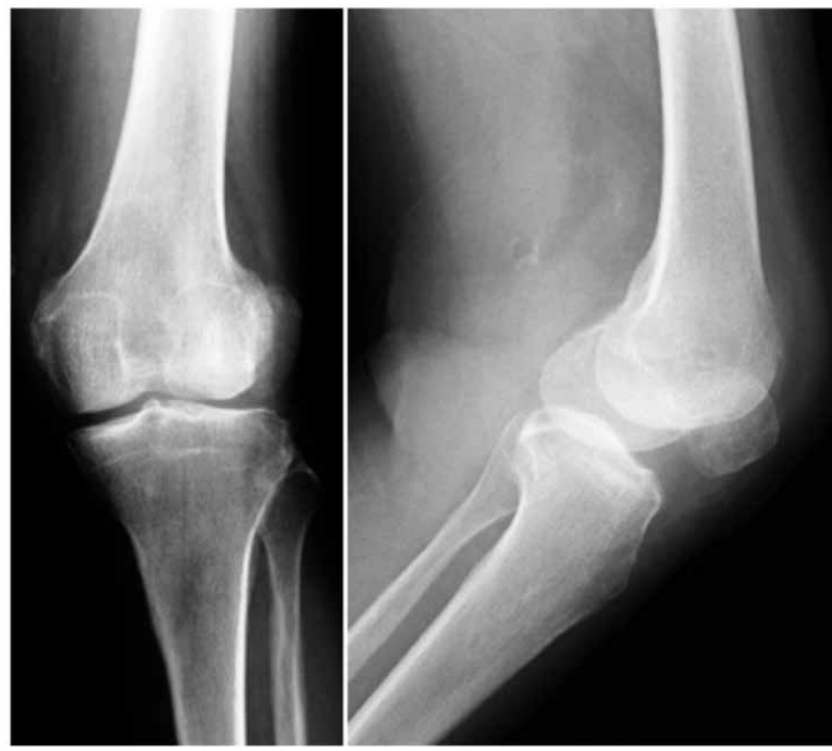

Şekil 1. Direkt grafide patellanın disloke olduğu görülmekte

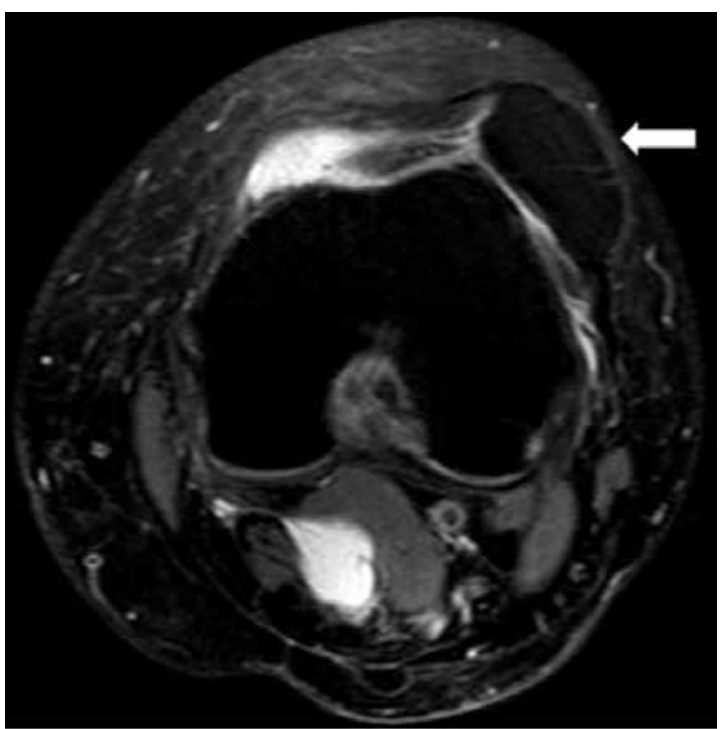

Şekil 2. Magnetik rezonans görüntülemesinde aksiyel kesitte ok disloke olmuş patellayı göstermekte
3). Daha sonra ekleme ulaşılarak standart şekilde femoral ve tibial kesiler yapıldı. Femoral kesi klasik $3^{\circ}$ dış rotasyon yerine $0^{\circ}$ nötralde uygulandı. Sırasıyla önce patellar tendondan quadriseps tendonuna kadar total lateral gevşetme yapıldı. Proksimal lateral quadriseps tendonuna parsiyel gevşetme yapıldı. Medial plikasyon ile patellanın femoral sulkusa oturduğu görüldü. Bağ kesen mobil insert ve sementle femoral ve tibial stemler yerleştirildi (Striker). Medial patellar retinakulum medialde cilt altı fasyaya sütüruze edildi. Subvastus adelesi gerdirilerek quadriseps tendonu distal lateraline ve patella lateral retinakuluma sütüre edildi (Şekil 4). Bu işlemle lateral patellar dolaşıma destek ve patellanın mediale gerdirilmesi amaçlandı. Katlar kapatılıp operasyona son verildi. Illk iki hafta $15^{\circ}$ ye kadar

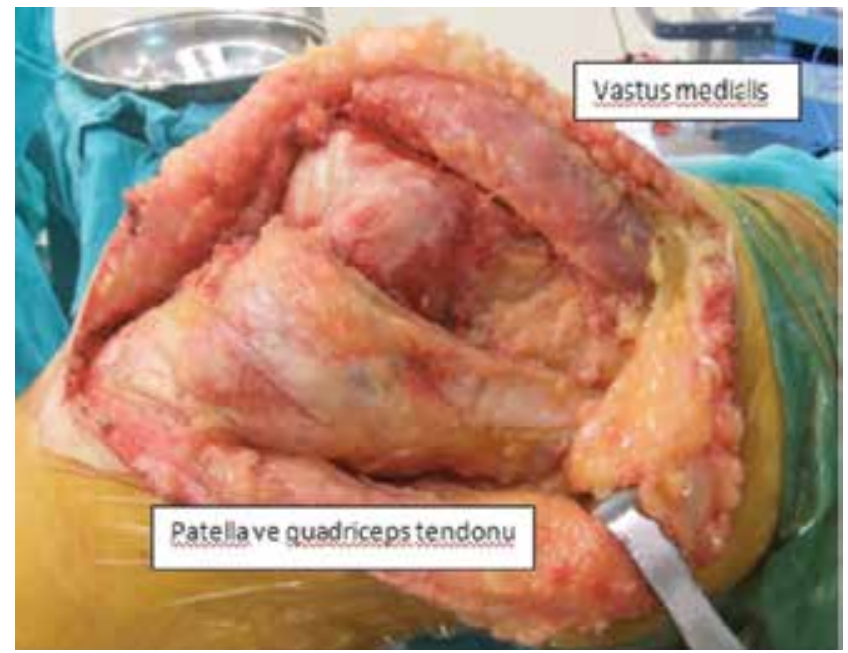

Şekil 3. Cerrahi sırasında patellanın ve quadriceps tendonunun laterale yerdeğiştirdiği ve vastus medialis kasının hipertrofiye uğradığı görüldü

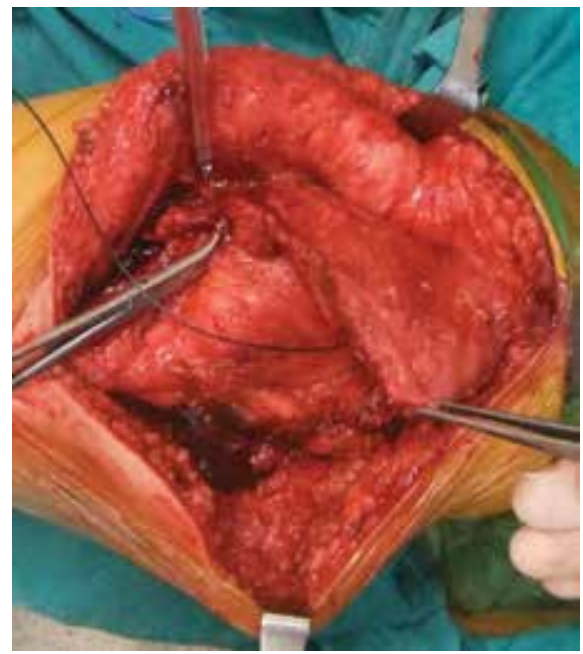

Şekil 4. Hipertrofiye uğramış vastus medialis destek amaçlı laterale suture edildi 


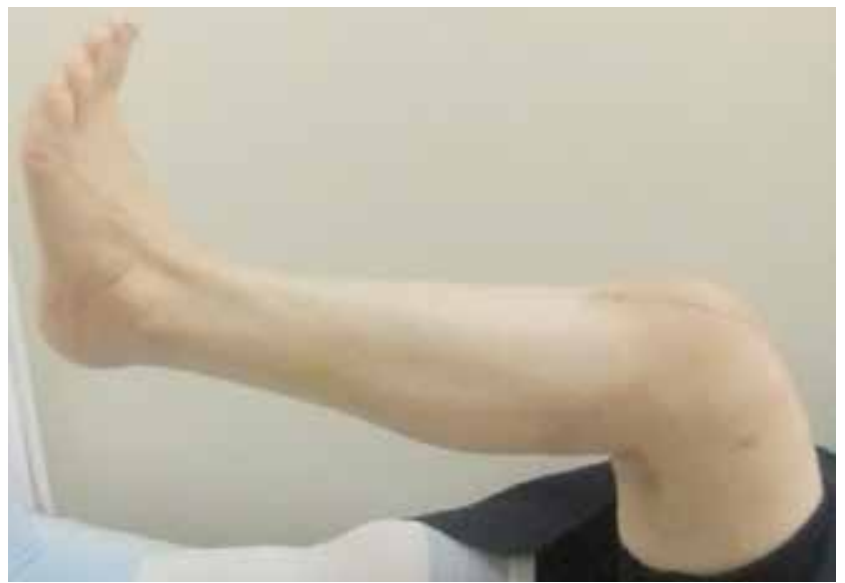

Şekil 5. Postoperatif dönemde dizde $100^{\circ}$ fleksiyona izin verildi

fleksiyona izin veren açı ayarlı menteşeli dizlik ile tam yüke izin verilerek hasta mobilize edildi. Sonraki iki hafta $45^{\circ}$ fleksiyona izin verildi ve quadriseps güçlendirici egzersizler başlandı. Dört hafta sonunda $90^{\circ}$ fleksiyona izin verildi ve yük kaldırma egzersizlerine başlandı. Toplam iki ay sonunda olgumuzun $100^{\circ}$ fleksiyon ve tam ekstansiyon yapabildiği görüldü (Şekil 5). Yüz derece üzerinde diz fleksiyonuna izin verilmedi. Toplam dokuz aylık takip sonunda aktif olarak $100^{\circ}$ fleksiyon ve tam ekstansiyon yapabilen, patellanın femural sulkusta olduğu ağrısız bir eklem elde edilmiş olundu.

\section{Tartışma}

Patella dislokasyonu travmatik ya da konjenital olarak görülebilmektedir $(1,2)$. Patella dislokasyonu hastalarda dizi ekstansiyona getirmede ve ekstansiyonda kilitlemede zorluğa neden olmaktadır. Travmatik olarak daha çok medialden alınan darbe sonrası laterale çıkık görülmektedir. Bu hastaların bir kısmında patella hipoplazisi, ligamentöz laksite, femoral hipoplazisi, ailesel genetik yatkınlık tesbit edilmekte ve bu durum yetersiz tedavi sonucunda kronikleşmektedir (3-7). Kronikleşmiş patella dislokasyonunun doğuştan mı yoksa travmatik mi olduğunu ayırt etmek zordur $(8,9)$.

Doğuştan patella dislokasyonunda kromozomal anomaliler, patella hipoplazisi, eklemlerde aşırı laksite olması patolojinin doğuştan olduğunu desteklemektedir. Literatürde travma sonrası inmal edilmiş ve kronikleşmiş patella dislokasyonu ile ilgili çok az sayıda makale yer almaktadır (10-12). Hastamızın anamnezinde travma öyküsü olmasının yanı sıra patellanın diğer patella ile aynı büyüklükte olması, hastanın diğer eklemlerinde laksite olmaması ve aile öyküsünün olmaması patolojinin sonradan gerçekleştiğini desteklemektedir.

Goldthwaite ve ark. 1899 'da travma sonrası redükte edilmemiş bilateral patella dislokasyonu olgusunu yayınlamamışlardır (13). Miller ve ark. da yine travma sonrası redükte edilmemiş 13 patella dislokasyonlu olgu serilerini bildirmişlerdir (14). Bu olgularda femural sulkus lateral yüksekliğin azaldığını tesbit etmişlerdir. Olgumuzda muhtemelen patellofemoral fonksiyonun olmamasına bağlı olarak femural patellar sulkusun azaldığını ve patellar eklem yüzeyinin düzleştiğini gözlemledik.

Tedavide izole patella dislokasyonlu hastalarda çeşitli yumuşak doku ve kemik osteotomi teknikleri ile başarılı sonuçlar bildirilmiştir (15-19). Ancak osteoartritle birlikte tedavi edilmemiş patella dislokasyonu nedeniyle total diz artroplastisi yapılmış çok az sayıda yayınlanmış bildiri olup standardize olmuş bir cerrahi yaklaşım bildirilmemektedir. Bullek ve ark. sadece travma sonrası ihmal edilmiş patella dislokasyonlu bir hastada dış rotasyon ve femur valgus deformitesi olduğunu, proksimal aksın sağlanarak ve kısıtlayıcı diz artroplastisi uygulanarak başarılı sonuç aldıklarını bildirmişlerdir (10). Yine Hudson ve ark. 2003'de inmal edilmiş travmatik patella dislokasyonu ile osteoartritik değişiklikler mevcut olan bir olguda total diz protezi ile başarılı sonuç aldıklarını bildirmişlerdir (11). Hastada valgus, instabilite ya da dış rotasyon deformitesi olmamasından dolayı kısıtlayıcı olmayan total diz artroplastisi uygulamışlardır. Femoral ve tibial stemleri dış rotasyonda uygulamanın yeterli olduğunu bildirilmektedir. Hastamızda valgus, instabilite ve dış rotasyon deformitesi yoktu, bu nedenle kısıtlayıc olmayan total diz protezi tercih ettik. Ancak Hudson ve ark.'ndan farklı olarak femoral stemin dış rotasyonda yerleştirilmesinin tersine biz $0^{\circ}$ nötralde femoral kesiyi yaptık. Yalnız bir vakanın yetersiz olmasına karşın travmatik veya doğuştan patella lateral dislokasyonlu olgularda femoral kesinin klasik dış rotasyon yerine nötralde kesilmesinin lateral desteği arttırmasından dolayı patellar dislokasyon riskini azaltacağını düşünmekteyiz. Young in ve ark. 2009'da travma sonrası ihmal edilmiş patella dislokasyonu ve osteoartriti mevcut olan iki hastaya uyguladıkları total diz protezi ile başarılı sonuçlarını yayınlamışlardır (12). Vastus lateralisten tüberositas tibiaya kadar lateral gevşetme yaptıklarını ve fleksiyon hareketinin kısıtlamasını engellediklerini belirtmişlerdir. Hudson ve Bullek standart medial prepatellar girişiminin ekstansör mekanizmayı zayıflattığını, vastus medialisin mediale çekme gücünü azalttığını ve medial vasküler dolaşımı bozarak patella osteonekroz riskini arttırdığını öne sürmüşlerdir ve bu nedenle subvastus yaklaşımı önermiştir. Hastamızda cilt, cilt altı katlar geçildikten sonra patellanın femur lateralinde olduğunu, vastus medialisin hipertrofik gevşek bir halde quadriseps tendon distal lateralinde birleştiğini gözlemledik. Klasik medial yaklaşımla vastus medialisi kaldırıp kapatma aşamasında medial patellar retinakulumu fasyaya sütüre ettik. Vastus medialisi gerdirerek quadriseps 
tendon distal lateraline ve patella lateral retinakuluma sütüre ettik. Aşırı lateral pateller tendon gevşetilmesi ise patella ve patellar tendon vasküler dolaşımına zarar vermektedir (20). Bu nedenle zorlayıc fleksiyonda pateller tendon rüptürü gelişebilmektedir. Bizde hastamızda patellanın femoral sulkusta olabilmesi için aşırı lateral pateller tendon gevşetmesi yaptık. Bu yüzden de patellar tendon rüptürüyle karşılaşmamak için hastamızda diz fleksiyonunu $100^{\circ}$ ile kısıtladık.

Sonuç olarak tedavi edilmemiş patella dislokasyonuna eşlik eden diz osteoartritinde total diz artroplastisi ile birlikte kemik ve yumuşak doku dengesi sağlanabilirse başarılı sonuçlar elde edinilebilirr. Femoral kesinin nötralde yapılması, lateral patellar tendonun gevşetilmesi ve zorlayıcı aşırı fleksiyon hareketinden kaçınılması olası komplikasyonları minimal seviyeye indirdiği düşüncesindeyiz.

\section{Kaynaklar}

1. Carragher AM, Todd A, Blake G. Acute traumatic lateralpatellar dislocation. Ann Emerg Med 1989;18:1362-3.

2. Eilert R. Congenital dislocation of the patella. Clin Orthop 2001;389:22-9.

3. McCarroll HR, Schwartzmann JR. Lateral dislocation of the patella. Correction by simultaneous transplantation of the tibial tubercle and semitendinous tendon. J Bone Jt Surg 1945;27:446-52.

4. Jensen CM, Roosen JU. Acute traumatic dislocation of the patella. J Trauma 1985;25:160-2.

5. Larsen E, Lauridsen F. Consevative treatment of patellar dislocation: influence of evident factors on the tendency to redislocation and the therapeutic result. Clin Orthop Relat Res 1982;:131-6.

6. Miller GE. Familial recurrent dislocation of the patella. J Bone Jt Surg 1978;60B:203-4.
7. Runow A. The dislocating patella. Etiology and prognosis in relation to generalized joint laxity and anatomy of the patellar articulation. Acta Orthop Scand Suppl 1983;201:1-53.

8. Marmor L. Total knee arthroplasty in a patient with congenital dislocation of the patella. Case report. Clin Orthop Relat Res 1988;226:129-33.

9. Miller MD, Hausman M, Jokl P, Lindsey RW. Permanent posttraumatic patellar dislocation. J Trauma 1988;28:1389-92.

10. Bullek DD, Scuderi GR, Insall JN. Management of the chronic irreducible patellar dislocation in total knee arthroplasty. J Arthoplasty 1996; 11:339-45.

11. Hudson J, Reddy VR, Krikler SJ. Total knee arthroplasty for neglected permanent post-traumatic patellar dislocation: case report. Knee 2003;10:207-12.

12. In $Y$, Kong CG, Sur YJ, Choi SS. TKA using the subvastus approach and lateral retinacular release in patients with permanent post-traumatic patellar dislocation: a report of two cases. Knee Surg Sports Traumatol Arthrosc 2009;17:254-9.

13. Goldthwaite JE. Permanent dislocation of the patella. Ann Surg 1899;29:62-8

14. Miller MD, Hausman M, Jokl P, Lindsey RW. Permanent posttraumatic patellar dislocation. J Trauma 1988;28:1389-92.

15. Scuderi GR. Surgical management of patellar instability. In: Scuderi GR, editor. The patella. New York: Springer-Verlag; 1995. p. 223.

16. Yamamoto RK. Arthroscopic repair of the medial retinaculum and capsule in acute patellar dislocations. Arthroscopy 1986;2:125-31.

17. Fulkerson J. Anteromedialization of the tibial tuberosity for patellofemoral malalignment. Clin Orthop Relat Res 1983;177:176-81.

18. Post WR, Fulkerson JP. Distal realignment of the patellofemoral joint. Indications, effects, results, and recommendations. Orthop Clin North Am 1992;23:631-43.

19. Taşkıran E, Lök V. Kronik patella çıkığında medial retinakuler yapıların anatomik rekonstrüksiyonu Acta Orthop Traumatol Turc 1995;29:436-9.

20. Rosenberg AG. Management of extensor mechanism rupture after TKA. J Bone Joint Surg Br 2012;94:116-9. 